\title{
Temperature Dependence of Ultrasonic Absorption in Mixtures of Glycerol and Water.
}

\author{
G. S. Darbari, R. P. Singh and G. S. Verma
}

Physics Department, Allahabad University - Allahabad

(Nuovo Cimento, $41 \mathrm{~B}, 15$ (1965))

$\left(\mathrm{CH}_{2} \mathrm{OH} \cdot \mathrm{CHOH} \cdot \mathrm{CH}_{2} \mathrm{OH}\right)_{4} \mathrm{H}_{2} \mathrm{O}$ should be $\left(\mathrm{CH}_{2} \mathrm{OH} \cdot \mathrm{CHOH} \cdot \mathrm{CH}_{2} \mathrm{OH}\right) \cdot \mathrm{H}_{2} \mathrm{O}$.

\section{Radiation-Induced Noise in Semiconductor Counters.}

A. Bertin, P. Gondi and G. Scandola

Istituto di Fisica dell'Università - Bologna

(Nuovo Cimento, $41 \mathrm{~B}, 198$ (1965))

The following misprints of this paper should be corrected.

The eaption of Fig. 1 was incorrect. Hereunder is published the figure with the correct caption.

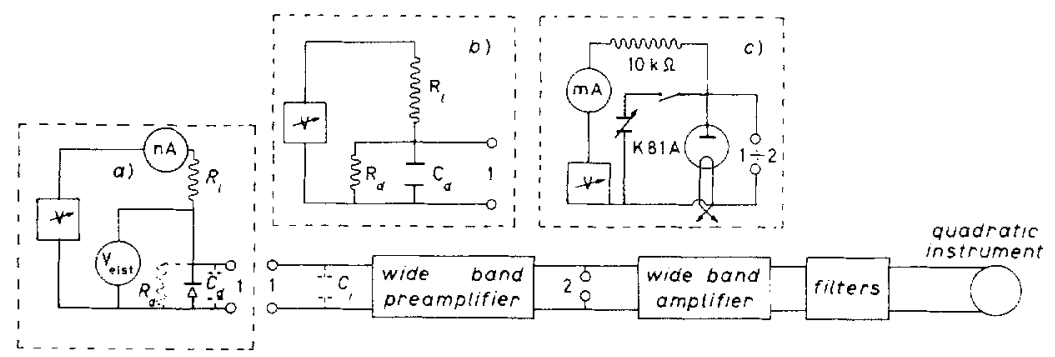

Fig. 1. - Scheme of the circuits used for the noise measurements: $a$ ), $b$ ) and c) are respectively the detector circuit, the detector-equivalent $R C$ circuit and the test eircuit, to be opportunely connected to the terminals as indicated by the numbers.

$$
\begin{array}{ll}
R_{l}=2 \cdot 10^{7} \Omega, & C_{d}=1.5 \cdot 10^{-10} \mathrm{~F}, \\
R_{d}=5 \cdot 10^{9} \Omega, & C_{i}=1.4 \cdot 10^{-8} \mathrm{~F} .
\end{array}
$$

In Table II of p. 203 read: reproduction errors of $30 \%$,.. instead of: reproducibility of errors of $30 \%$....

In the caption of Fig. 5 read $\overline{m_{r}^{2}} / \bar{m}_{r}$ values instead of $\overline{m_{r}^{2}} / \bar{m}_{\tau}^{2}$ values. 